\title{
Erratum to: Polymorphic SVA retrotransposons at four loci and their association with classical HLA class I alleles in Japanese, Caucasians and African Americans
}

Jerzy K. Kulski • Atsuko Shigenari • Hidetoshi Inoko

Published online: 28 May 2010

(C) Springer-Verlag 2010

\section{Erratum to: Immunogenetics}

DOI 10.1007/s00251-010-0427-2

The original version of this article unfortunately contained a mistake. The presentation of Fig. 2 is incorrect. The corrected figure is given below.

The online version of the original article can be found at http://dx.doi. org/10.1007/s00251-010-0427-2.

J. K. Kulski

Centre for Forensic Science, The University of Western Australia,

Nedlands, Western Australia 6008, Australia

J. K. Kulski • A. Shigenari $\cdot$ H. Inoko

Division of Molecular Life Science,

Department of Genetic Information, School of Medicine,

Tokai University,

Isehara, Kanagawa, Japan

\section{J. K. Kulski ( $\square)$}

Centre for Forensic Science, The University of Western Australia, Mailbag M420, 35 Stirling Highway,

Crawley, Western Australia 6009, Australia

e-mail: kulski@me.com 
a. SVA-HA (primer set $2 a$, insertion and absence)

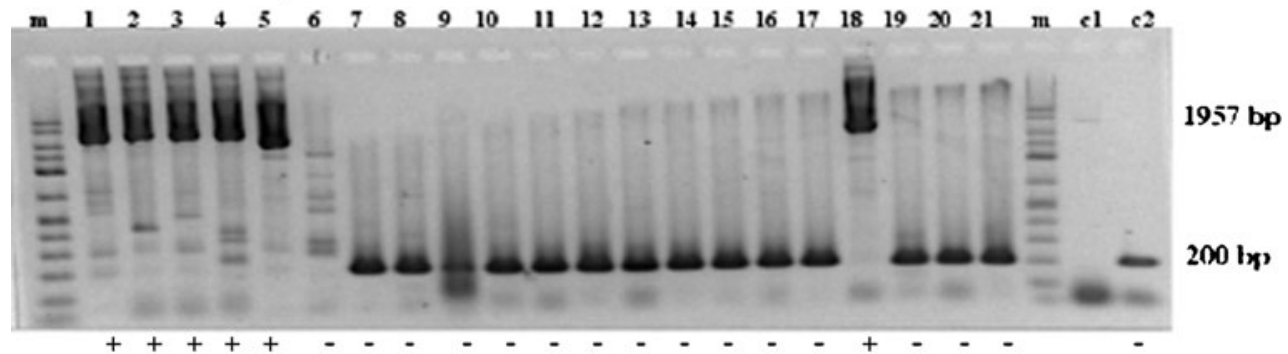

b. SVA-HA (primer sct 2c, inscrtion only)

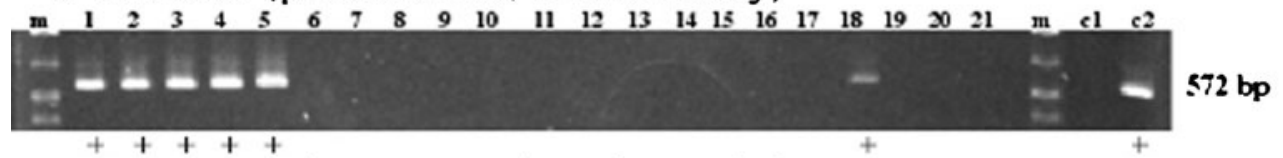

c. SVA-HF (primer set $6 c$, insertion and absence)

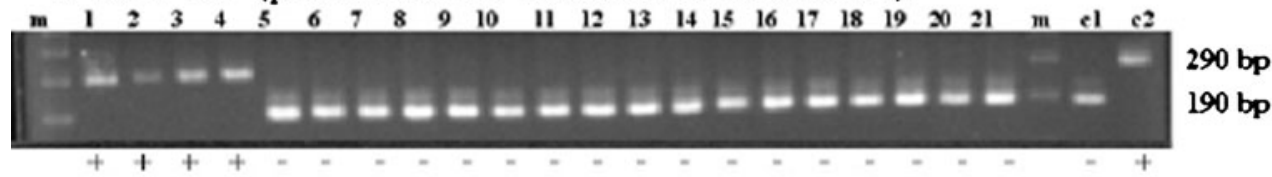

d. SVA IIC (primer set 3a, insertion and absence)

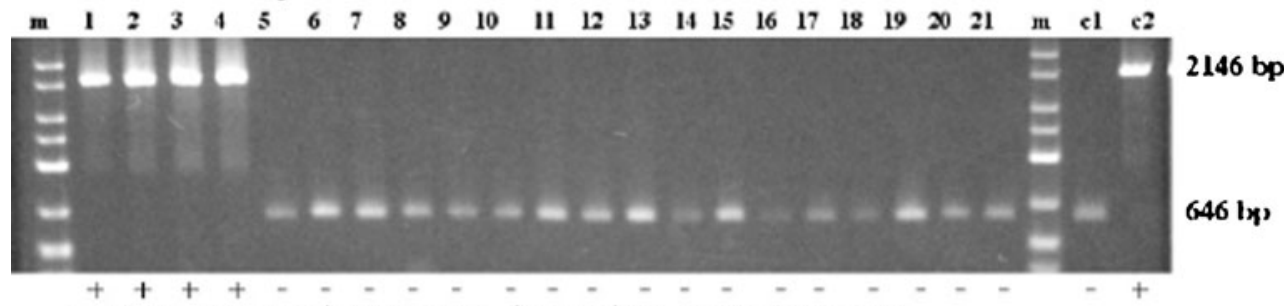

e. SVA IIB (primer set 5 , insertion and absence)

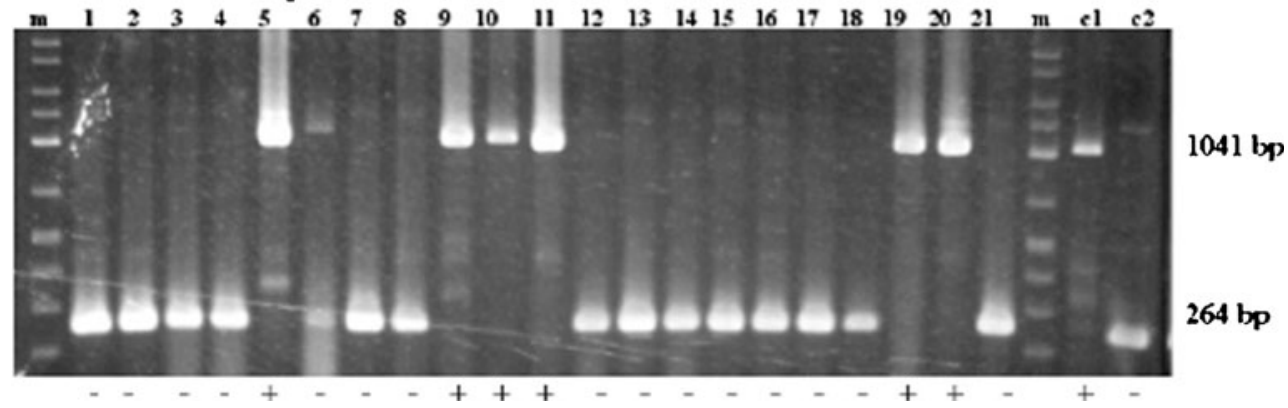

